\author{
SUPPLEMENTAL REBUTTAL REPORT \\ REGARDING THE ARCO INSTREAM FLOW STUDY \\ ON THE CLARK FORK RIVER
}

\title{
JANUARY 1996
}

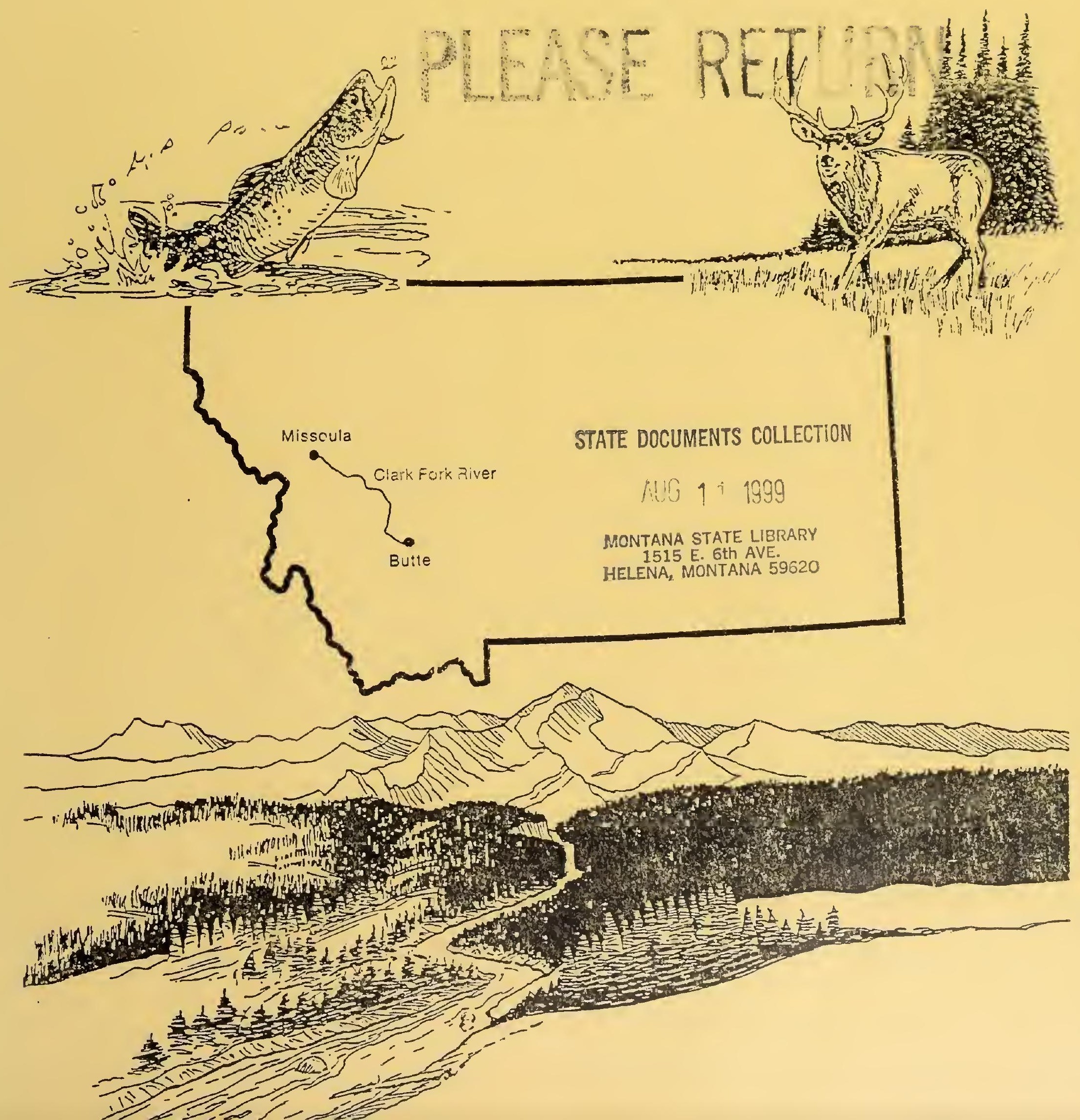


$62 \varepsilon \cdot 16$ Supelemental

$42 \leq r$ rebuttal report

$12 \leqq r$

reearding the

instream low

study on the Clark

Fork Fiver

UAIC UUC

\begin{tabular}{|l|l|l|l|}
\hline & \multicolumn{1}{|c|}{ 8 $19 \mathrm{dg}$} & & \\
\hline & & & \\
\hline & & & \\
\hline & & & \\
\hline & & & \\
\hline & & & \\
\hline & & & \\
\hline & & & \\
\hline & & & \\
\hline & & & \\
\hline
\end{tabular}

MONTANA STATE LIBPARY

1515 Eant 6th Avenue

Heluin. MT 59620-1800

AUG 1 i 1999 


\section{Supplemental Rebuttal Report}

Regarding the ARCO Instream Flow Study

on the

\section{Clark Fork River}

Prepared by:

Tim Hardin, Ph.D.

Hardin-Davis, Inc.

Albany, OR

January 26, 1996 



\section{Supplemental Rebuttal Report}

\section{Regarding the ARCO Instream Flow Study \\ on the}

\section{Clark Fork River}

Prepared by:

Tim Hardin, Ph.D.

Hardin-Davis, Inc.

Albany, OR

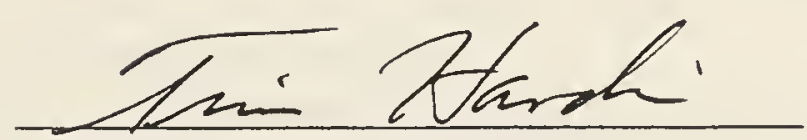

January 26, 1996 
Digitized by the Internet Archive in 2015 
Supplemental Rebuttal Report Regarding the ARCO Instream Flow Study on the Clark Fork River

\section{INTRODUCTION}

An instream flow study was done for ARCO by EA Engineering in 1988-89 on a number of sites in the Clark Fork River (CFR). Results and conclusions of the study were discussed in several $\mathrm{ARCO}$ documents, including:

1). EA Engineering: Instream Flow Study, Clark Fork River Aquatic Ecology Studies, Volume 1, June 1990 (draft)

2). R2 Consultants: Appendix E. An evaluation of the key biotic and abiotic factors potentially influencing the relative abundance of brown trout and rainbow trout in the Upper Clark Fork River, Montana.

3). R2 Consultants: Appendix F. Assessment of the longitudinal changes in total fish biomass within the Upper Clark Fork River, Montana.

The focus of this review is on the first document, since it contains most of the technical information.

The instream flow study done for ARCO is outlined in a flow chart (Figure 1). The stated objectives were to develop a relationship between fish habitat and flow, and to determine the degree to which streamflow might limit populations in the CFR. Based on the results of the study, certain conclusions were reached. Among these conclusions were

A) Fry habitat is always limiting, and could contribute to low trout populations

B) Low flows limit adults during certain periods

C) The distribution of brown and rainbow trout is partly explained by the distribution of weighted usable area (WUA) in the Clark Fork.

The following review will show that serious flaws exist in the study design, data collection, and model extrapolation, and questions remain concerning other parts of the study. As a consequence, the WUA output is unreliable. The unreliable WUA data underwent further treatment by EA through the application of habitat ratios. These ratios were not based on data, but rather on broad assumptions and speculation. The combination of such an interpretation technique, built on a foundation of poor WUA data, means that the end result ("total habitat in the CFR") is not meaningful. Thus, no conclusions can be drawn from the EA report. 


\section{Simulation Sequence for Assessing Instream Flow: Habitat Relationships using the Instream Flow Incremental Methodology}

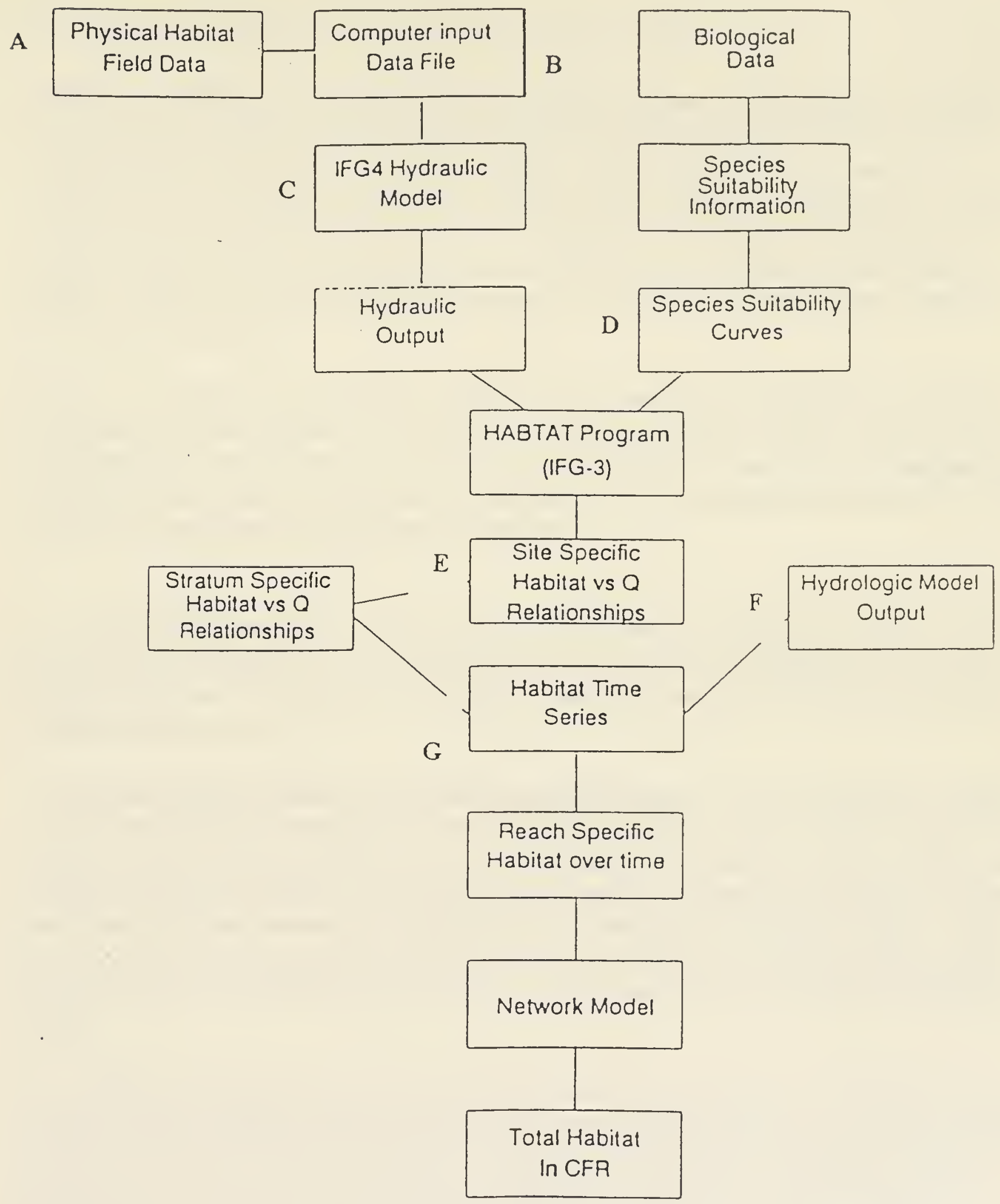

Figure 1. Individual steps in the instream flow study conducted by EA. (Figure taken directly from $E A$ report; bold capital letters added in reference to items discussed in this review 



\section{II) REVIEW OF INDIVIDUAL PARTS OF THE STUDY}

Instream flow studies commonly rely on a methodology known as the Physical Habitat Simulation (PHABSIM). This is a set of models that relates changes in the amount of usable habitat for fish species to changes in flow (discharge). Key components in the system are 1) the hydraulic simulation models (the most common being the IFG-4 model), which quantify depths and velocities as they change with flow, and 2) the HABTAT model, which translates physical values into an index of usable habitat termed Weighted Usable Area (WUA). The relationship between WUA and flow is the primary output of the PHABSIM method.

Figure 1, taken from the EA report, outlines steps taken in the PHABSIM data collection, processing and interpretation. As the figure shows, a PHABSIM study is made up of a large number of interrelated steps, and the accuracy of the end product ("total habitat in the CFR") depends on the accuracy of the individual steps. I have marked several of the boxes in Figure 1 for reference throughout this review.

A. Physical Habitat Field Data. This is the foundation for a PHABSIM study. There is little point in calculating WUA with poor field data. EA made a significant error in the timing of field work. In addition, a review of their field notes shows that serious errors in techniques were common.

1. The authors did not collect all the data in one field season. It is a cardinal rule, taught in every PHABSIM field techniques course for at least the last 15 years, to collect all the data during one field season, preferably on the descending limb of the hydrograph. (Trihey and Wegner 1981; Bovee 1993) The reason for this is simple: if the data are collected so that peak flows intervene between field trips, the risk of streambed movement is great. If the streambed moves, this will alter the distribution of velocities across a given transect, and it can also alter the stage-discharge relationship, which is at the heart of the IFG-4 hydraulic model.

For virtually all of the 27 sites measured by EA, the low or mid-flow measurements were done in the fall of 1988, and the high flow was done the following June. In the intervening months, peak flows occurred ( Table 1), making major streambed movement a strong possibility. In fact, flows were evidently sufficiently high to cause at least 16 headpins to disappear, and to erode away the streambank in at least one location (Appendix 1).

If streambed movement is suspected, it is a simple matter to test for it. If the bottom profile for a transect is compared before and after a peak flow event, changes due to scour and deposition are easy to detect. If the changes are significant, then the stage-discharge relationship is invalidated. To my knowledge, such tests were not carried out by EA. Thus, considerable doubt remains on this subject. 

Table 1 Peak flows (a) that occurred at 5 gaging stations within the study area on the Clark Fork River between the time of EA's first and second data field trips.

\begin{tabular}{ll} 
Gaging station & Peak flow $(\mathrm{cfs})$ \\
\hline Galen & 552 \\
Deer Lodge & 858 \\
Goldcreek & 2240 \\
Clinton & 2960 \\
Turah & 4460 \\
\hline
\end{tabular}

(a) Values reported are maximum daily flows, which are typically less than instantaneous peak flows. 

In summary,

- The study should (and could) have been designed such that all three sets of data were collected in one field season.

- Failing this, the authors should have tested numerous transects for bed movement.

- If significant bed movement was found, then the authors should have collected an additional set of data in 1989, to replace the 1988 measurements.

\section{2). Proper surveying techniques were not followed.}

a) Level loops: The concept of a level loop is fundamental to the process of surveying elevations. The basic idea is to start with a reading on a benchmark, which is the permanent vertical reference point (usually designated 100.00 feet, by convention) for the study area. A reading on the benchmark establishes the height of the instrument $(\mathrm{HI})$. Using this calculated $\mathrm{HI}$, the surveyor can determine the elevations of other points in the study area. At least once, the instrument should be moved and re-leveled. A new HI is determined based on one of the points already surveyed. Then, points are shot a second time. A point is "closed" if two independent determinations of its elevation match. Without this procedure of closure, erroneous readings can remain undetected in the field notes. Closing on the benchmark and other vertical reference points is stressed as mandatory in the PHABSIM manuals (Trihey and Wegner 1981) and in the USFWS workshops on field techniques.

b) Level loops were often improperly done by EA. At several sites, all elevations were shot from a single instrument set-up in 1988 (Appendix 2). This means the vertical relationships between the benchmark (BM), headpins (HP) and water surface (WSEL) were unverified. This deficiency took on critical importance later in the study, because, in 1989 , at least seven of the original 27 benchmarks could not be found, and many headpins were alleged to have changed significantly in elevation over the winter and spring. In the absence of a permanent benchmark, and without a closed level loop on the headpins, there is no reliable reference point (vertical control) for any of the elevations at a site. Hence, conversion of the field data into an IFG-4 computer model becomes guesswork. The modeler had no way to determine whether discrepancies were due to actual physical changes (headpin movement), instrument malfunction, errors in technique, or some combination of the three.

For example, the notes for October, 1988, at site 3-1.1 plainly show that the loop was not closed (Appendix 2) All the elevations were shot once, from a single instrument set-up. Discrepancies were found here after subsequent field trips. Headpin elevations varied by as much as $0.41 \mathrm{ft}$ or 20 times accepted tolerance. Without a closed level loop, localizing the source of error is an uncertain process. In total, level loops were not closed during the first field visit on at least 4 sites, and during subsequent field visits at 15 or more sites. 
2. The crews did not refer to previous results on return trips to sites. On return trips to a study site, it is fundamental that the field crew refer to previous notes from the same site to keep a running check on their accuracy. In other words, if the elevation of Headpin X was measured at 99.50 feet on the first trip, the crew should recalculate its elevation on this trip and compare. If it does not come out right, they should try to reconcile the difference in the field. . Otherwise, field mistakes have to be resolved by guesswork in the office. Above all, the crew should refer to previous data in order to make sure that their present determination of instrument height $(\mathrm{HI})$ is correct. A crew that does not follow these procedures is merely writing down numbers and hoping for the best.

At 15 or more sites (Appendix 3), the crew did not attempt to calculate $\mathrm{HI}$ in the field. Without this basic procedure, neither could they attempt to calculate any water surface elevations (WSEL) on-site. Major discrepancies were later found at some of these sites. Without an effort to reconcile them in the field, EA left it up to the computer modeler to fill in the values. Again, the modeler had no way to determine the source of the discrepancies, and adjustments were necessarily guesswork.

For example, at site 3-2.1, the crew did not find the correct $\mathrm{HI}$ on the 2nd trip, in June, 1989 , because the benchmark could not be located. When a benchmark is lost (and this should be a very rare event), an experienced crew should still be able to get an acceptable HI using previously-surveyed headpins. This was not done. It appears that, two months after the fact, another individual did attempt (in the office) to reconcile the headpin elevations, based on notes in the margin. However, the calculations are based on survey results from a month after this one.

It turns out that if the crew in June had merely used the previous (October) value for Headpin 1, and added the backsight to it, that a reasonable approximation of $\mathrm{HI}$ would have emerged, and elevations for at least the first few headpins would have been in the ballpark: $(+/-0.07)$. The point here is that the crew did not even attempt this very basic procedure to reconcile the $\mathrm{HI}$. We do not know for sure why they did not, but we do know that this is a demonstration of poor technique.

3. There were frequent, major discrepancies in surveved elevations. At most sites, Headpin (HP) elevations could not be reconciled to within anywhere near acceptable tolerance limits. For most studies, acceptable tolerance limits are about $+/-0.02 \mathrm{ft}$ (Trihey and Wegner 1981). In the real world, discrepancies are occasionally slightly more, and minor adjustments need to be made in data processing. However, the EA field data, as summarized by Paul DeVries, (Appendix 4) show discrepancies that are far beyond acceptable limits for nearly every site (Table 2). Of 25 sites for which more than one set of measurements was taken, their maximum error in headpin surveying was above 0.02 at every single site. The errors were not small: at $88 \%$ of the sites, the discrepancies were over $0.20 \mathrm{ft}$, thus over ten times acceptable limits. (Table 3 ) This is a strong indication that Water Surface Elevations (WSEL) were measured inaccurately, and that the IFG-4 models are not reliable. It is interesting to note that EA discarded just two sites (3-1.3 and 3-2.3) due to "extreme headpin movement". Were results at these two sites really that much worse than the rest? 

Table 2. Headpin surveying discrepancies at 27 EA study sitess

Site

211

212

213

221

222

223

311

312

313

321

322

323

411

412

413

421

422

423

511

512

513

521

522

523

611

612

$\underline{613}$
Discrepancy Comments

0.50

0.20

0.23

0.38

0.43

0.35

0.41

0.21

4.15

1.51

0.13

0.99

0.05

0.59

2.99

3.94

NA

NA

1.23

9.85

8.21

0.47

3.34

0.51

6.91

0.35

4.75 further details in this review

site dropped by EA

further details in this review one column of numbers missing site dropped by EA

only one set of field notes

only one set of field notes

Discrepancies were calculated from the field note summary done by EA (Appendix 4 in this review). 

Table 3. Range of discrepancies in the EA headpin surveys at 25 sites

Error range $(\mathrm{ft}) \quad$ Number of sites Percentage of sites

$0-0.02$

0.03-0.10

$0.11-0.20$

0.21-0.50

0.51-1.00

$>1.00$

\begin{tabular}{ll}
0 & 0 \\
1 & 4 \\
2 & 8 \\
9 & 36 \\
3 & 12 \\
10 & 40 \\
\hline
\end{tabular}

Based on field data summary done by EA (Appendix 4 in this review). All sites are beyond tolerance limits. 

An important distinction needs to be made. Certainly, minor adjustments are made by most IFG-4 modelers in the course of calibration. These are usually on the order of a few hundredths of a foot in WSEL, and they should be based on real data. For example, the modeler might elect to omit the left WSEL measurement at a particular transect, or adjust a minor discrepancy in the benchmark elevations. That is not at issue here. In the present case, major adjustments had to be made at nearly every site. Again, critical field data upon which to base these major adjustments are simply lacking because of errors in technique. The resulting IFG-4 models can be no better than crude approximations.

\section{The EA data sheets do not include any measurements for Stage of Zero Flow (SZF).}

This is a key factor in the simulation of WSEL's, and it is a standard part of field data collection. Without a measurement, the modeler is forced to use the lowest point on the transect, or make a guess.

B) Computer input files We have not yet assessed the procedures used to generate the water surface data used in EA's IFG-4 computer input files. To date, we have not done an exhaustive review of the calibration techniques used. However, important questions include:

1. Who was in charge of calibrating all the IFG-4 and WSP models?

2. How were data discrepancies reconciled? We have seen that discrepancies were the rule, not the exception. It is essential that the adjustments be explained, in order to judge whether the adjustments are based on data or guesses.

3. Was it possible for the modeler(s) to distinguish "headpin movement" (EA's explanation) from errors in technique and/or faulty instruments?

\section{C) Over-extrapolation of the hydraulic models}

1. For all of the EA sites, the range of measured flows is less than what is recommended. The best results are obtained with the IFG-4 model if the high and low flows are separated by a factor of 10 or more (Milhous et al. 1989; Bovee 1993). For example, if the low measured flow is $40 \mathrm{cfs}$, the high measured flow should ideally be at least $400 \mathrm{cfs}$. A factor of at least 5 is recommended for reasonable behavior of the model. Of the $27 \mathrm{EA}$ sites, none had a flow range of 10 or more; and only 9 (one-third of the sites) had a range of 5 or more. Thus, two-thirds of the sites had measured flow ranges less than recommended values. In practice, hydrologic conditions and concerns for safety often preclude crews from obtaining an optimal flow range. The study can still proceed, but the investigators should realize that a smaller measured flow range means a smaller extrapolation range.

2. Regardless of (1), EA went beyond the extrapolation limits. The USFWS "rule of thumb" indicates that extrapolation should be limited to about 2.5 times the highest measured flow and 0.4 times the lowest measured flow. These guidelines presume that the 
highest measured flow is around 10 times the lowest measured flow. Yet EA went beyond these limits, based on their measured WSEL's and velocities (Table 4).

The farther one pushes the model beyond measured flows, the more unreliable the results become. It is an obvious conclusion that if a less-than-adequate flow range is measured, and yet the models are still extrapolated beyond accepted guidelines, then the results stray from reality.

\section{D) Suitability curves}

Suitability curves relate physical factors (depth, velocity, substrate) to fish "preference". They are a key part of the PHABSIM system, and often a source of contention. Suitability curves can be developed on-site, or they can be developed by consensus, or "standard" published curves can be used.

EA made use of various published curves, but modified them in-house. These curves were not reviewed by any outside parties, thus, they cannot necessarily be accepted at face value. Further examination of the curves by an outside party is warranted. Suitability curves do exert a great influence on WUA, so this is an important issue.

\section{E) The site-specific WUA vs $Q$ relationships are not reliable.}

The accuracy of WUA output is no better than the weakest of the individual components. In this case, potential problems exist in the suitability curves and many serious, demonstrable flaws exist in the field data. Thus, the site-specific WUA relationships are far below acceptable standards.

\section{F) Hydrology model}

The hydrology model only approximates flow's at the various reaches analyzed by EA. We have not had occasion to carry out an exhaustive review of the hydrology model, However, according to EA's own estimates ("Appendix K" 10412-10413), the simulated flows averaged about $24 \%$ less than measured flows. In the real world, precise hydrological figures may be difficult to come by; however, this step of the flow chart adds one more layer of uncertainty to the final product.

\section{G) Habitat Ratios}

Habitat ratios (Bovee 1982) use information about fish density, mortality rates, growth rates, and other factors to compare WUA for different life stages. In other words, units of WUA for fry and juvenile fish might be expressed in terms of their equivalents in adult 

Table 4. Numbers of sites extrapolated outside recommended limits.

Extrapolation(ft) Number of sites Percentage of sites

Based on highest water surface measurement

Over 2.5 times

6

$24 \%$

Over 5 times

$14 \%$

Based on highest velocity measurement

Over 2.5 times

17

$68 \%$

Over 5 times

4

$16 \%$ 

WUA. Theoretically, it is possible to determine, for a given range of flows, which life stage is limiting the population as a whole.

Even if we were to assume that the EA WUA figures at each site are accurate (which is not the case), the transition from these figures to conclusions regarding limiting life stages would require a very large leap of faith. This is because the derivation of habitat ratios relies on the calculation of at least 12 interrelated factors (Bovee 1982), including, for example, density of fry per unit WUA, and survival rate from fry to juvenile. Uncertainty exists in most of the factors, meaning the end result could vary greatly, depending on the assumptions used to derive each factor. EA did not calculate any of these factors, but instead applied a "professional judgment" habitat ratio. We have no way of knowing whether it bears any resemblance to reality.

\section{SUMMARY}

1. Proper field techniques were often not followed. Discrepancies in many of the data sets are alarmingly large; reconciling the discrepancies is difficult or impossible because of the failure to follow proper procedures. These flaws alone constitute grounds to invalidate EA's conclusions.

2. It is likely that streambed movement occurred between fall and summer measurements. If streambed movement has been tested for, we have not been supplied with the results. Significant streambed movement could invalidate results at any number of sites.

3. The range of flows collected was generally inadequate; nonetheless, the models were generally extrapolated beyond accepted limits.

4. The concept of habitat ratios was used to deduce limiting life stages. It would be difficult or impossible to evaluate the validity of claims made on the basis of assumed habitat ratios.

5. Uncertainties exist regarding the validity of the suitability curves and the hydrologic model.

6. Uncertainties remain regarding the adjustments made to field data during the calibration process.

EA has carried out a PHABSIM study, and used the results from 25 sites to reach conclusions regarding limiting life stages and limiting flows. Based on errors in the individual steps in their study, and the interrelationship of those steps, one is forced to conclude that their end product is not valid, and that no conclusions can be reached based on the study. 


\section{LITERATURE CITED}

Bovee, K.D. 1982. A guide to stream analysis using the Instream Flow Incremental Methodology. Instream Flow Information Paper 12. U.S. Fish and Wildlife Service. FWS/OBS-82/26.

Bovee, K.D. 1993 Data collection procedures for the Physical Habitat Simulation System. U.S. Fish and Wildlife Service (Draft).

Milhous, R.T., M.A. Updike, and D.M. Schneider. 1989. Physical Habitat Simulation System Reference Manual - Version II. Instream Flow Information Paper 26. U.S. Fish and Wildlife Service. FWS/OBS-89/16.

Trihey, E.W., and D.L. Wegner. 1981. Field data collection procedures for use with the Physical Habitat Simulation System of the Instream Flow Group. U.S. Fish and Wildlife Service. (Draft). 

Appendix 1. Examples of lost headpins and benchmarks, from EA field notes 


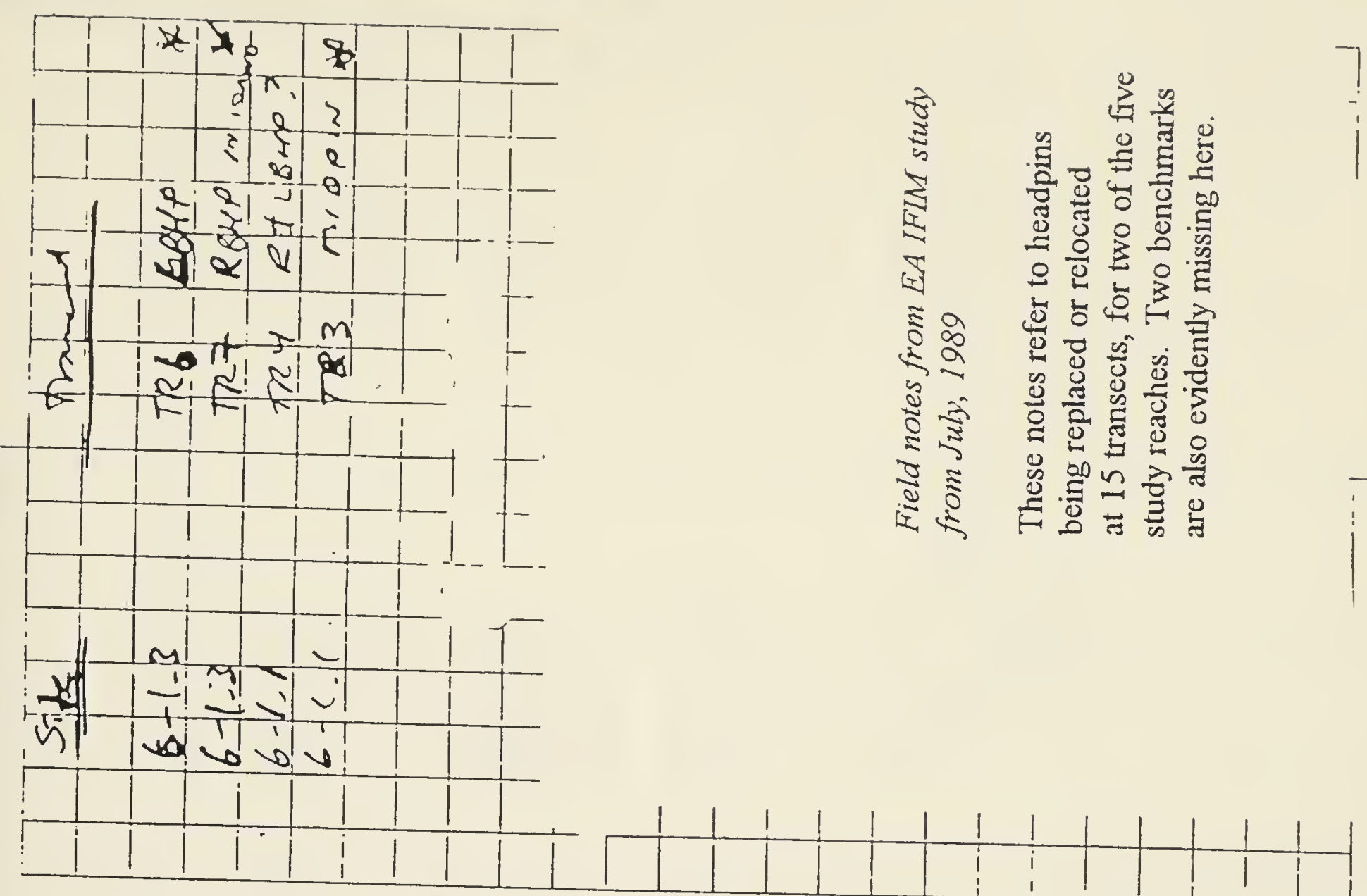



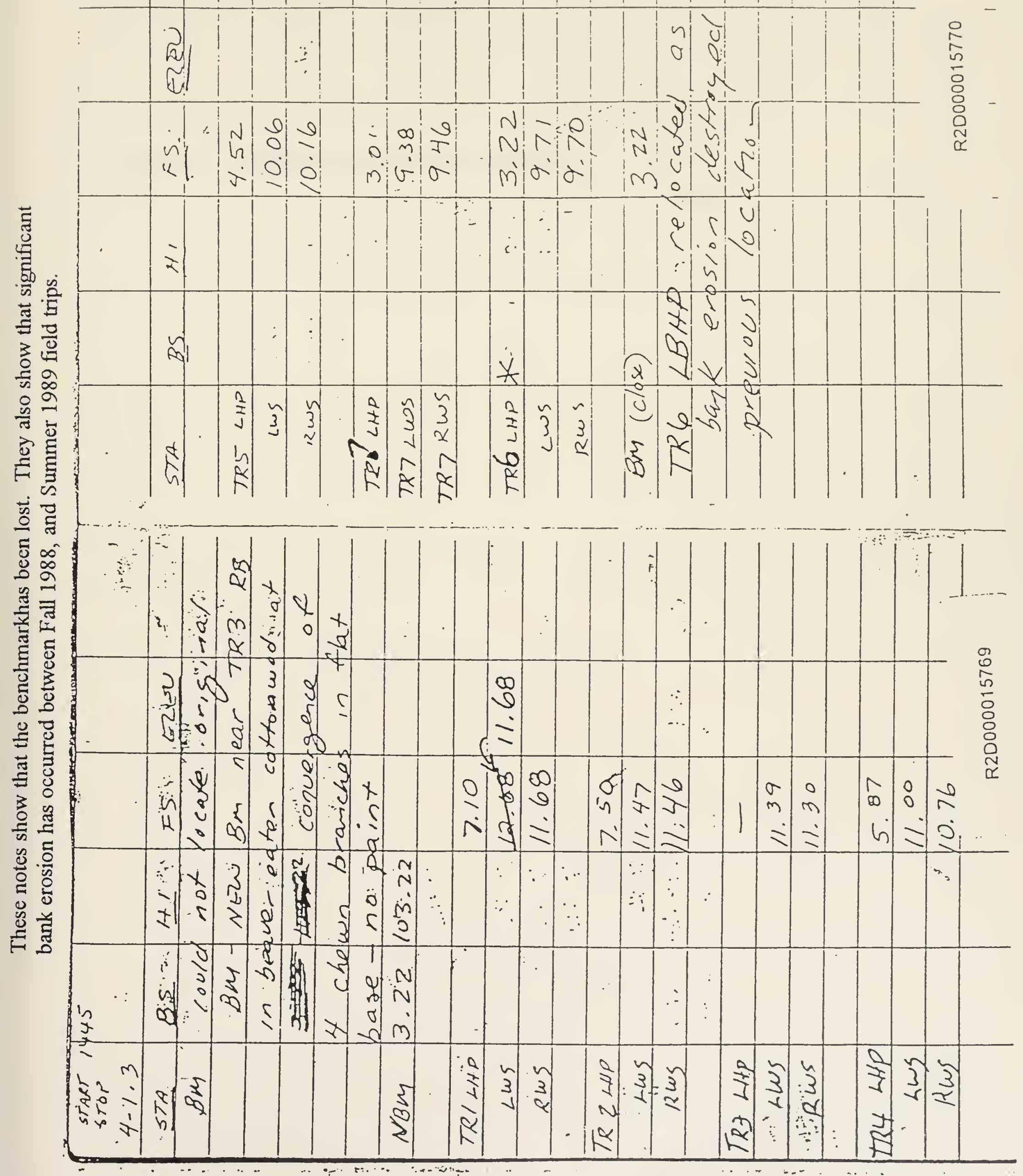



Appendix 2. Examples of failure to close level loops. 



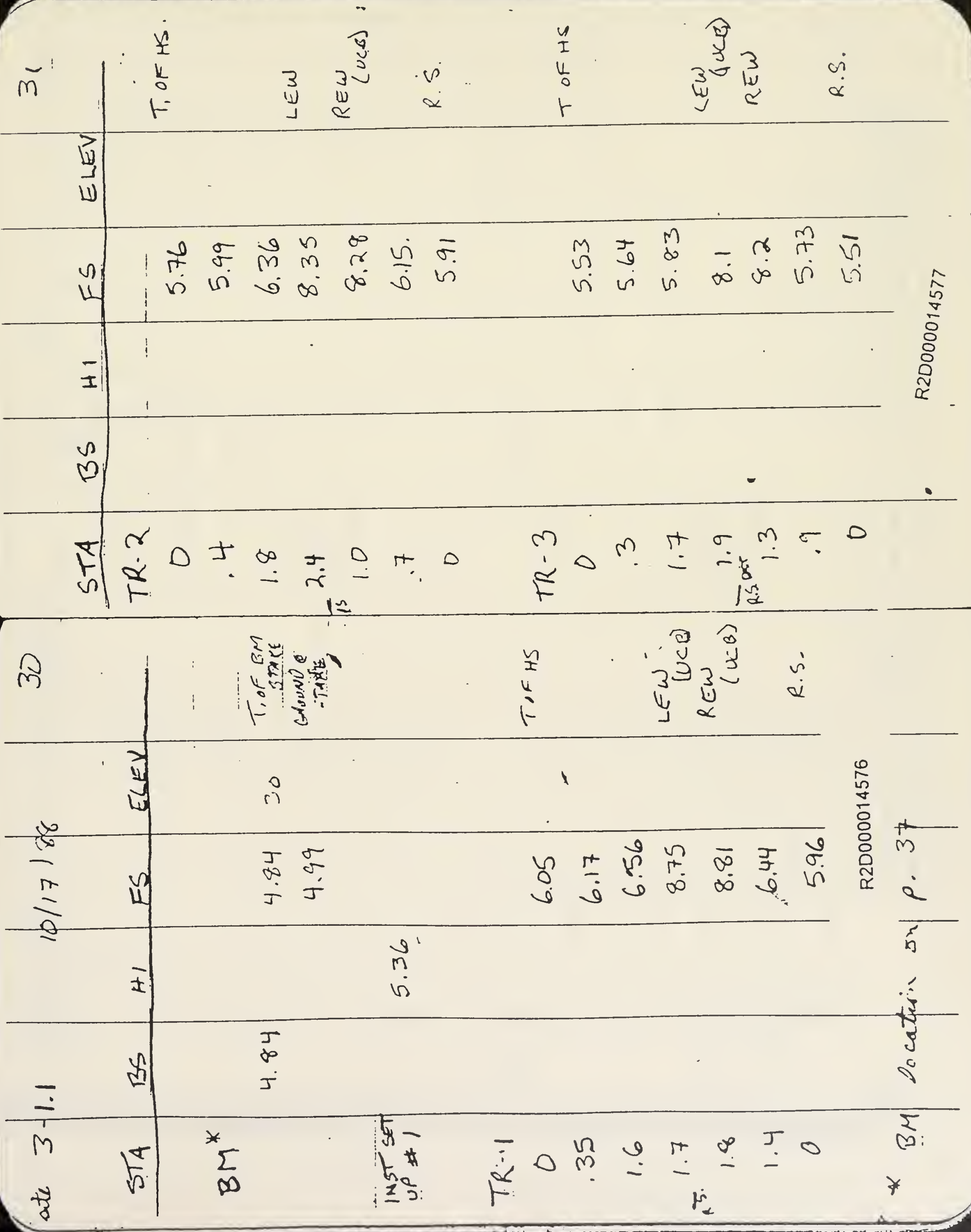

Ixpos 



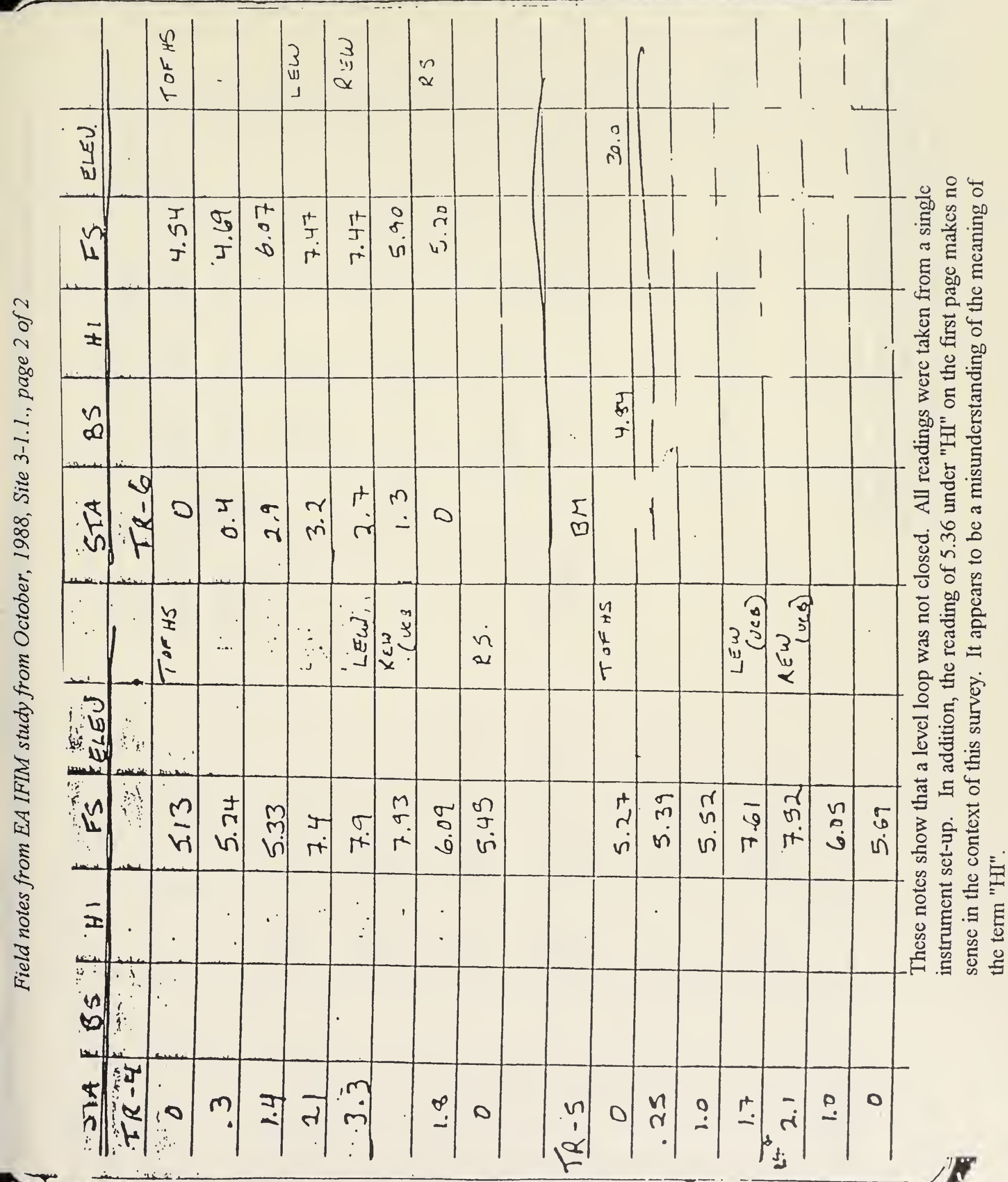



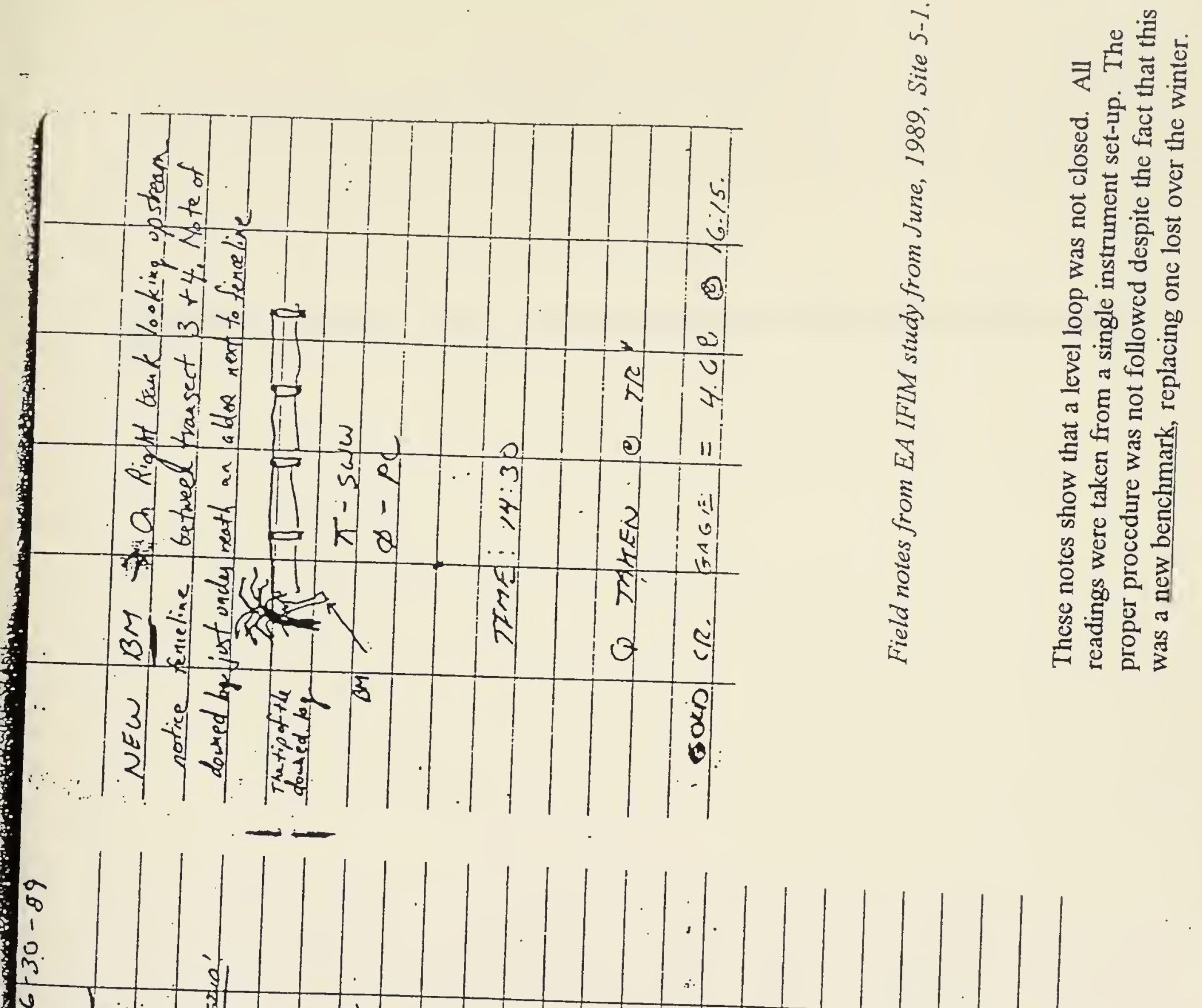

Appendix 3. Examples of failure to attempt calculation of $\mathrm{HI}$ and other elevations in the field. 



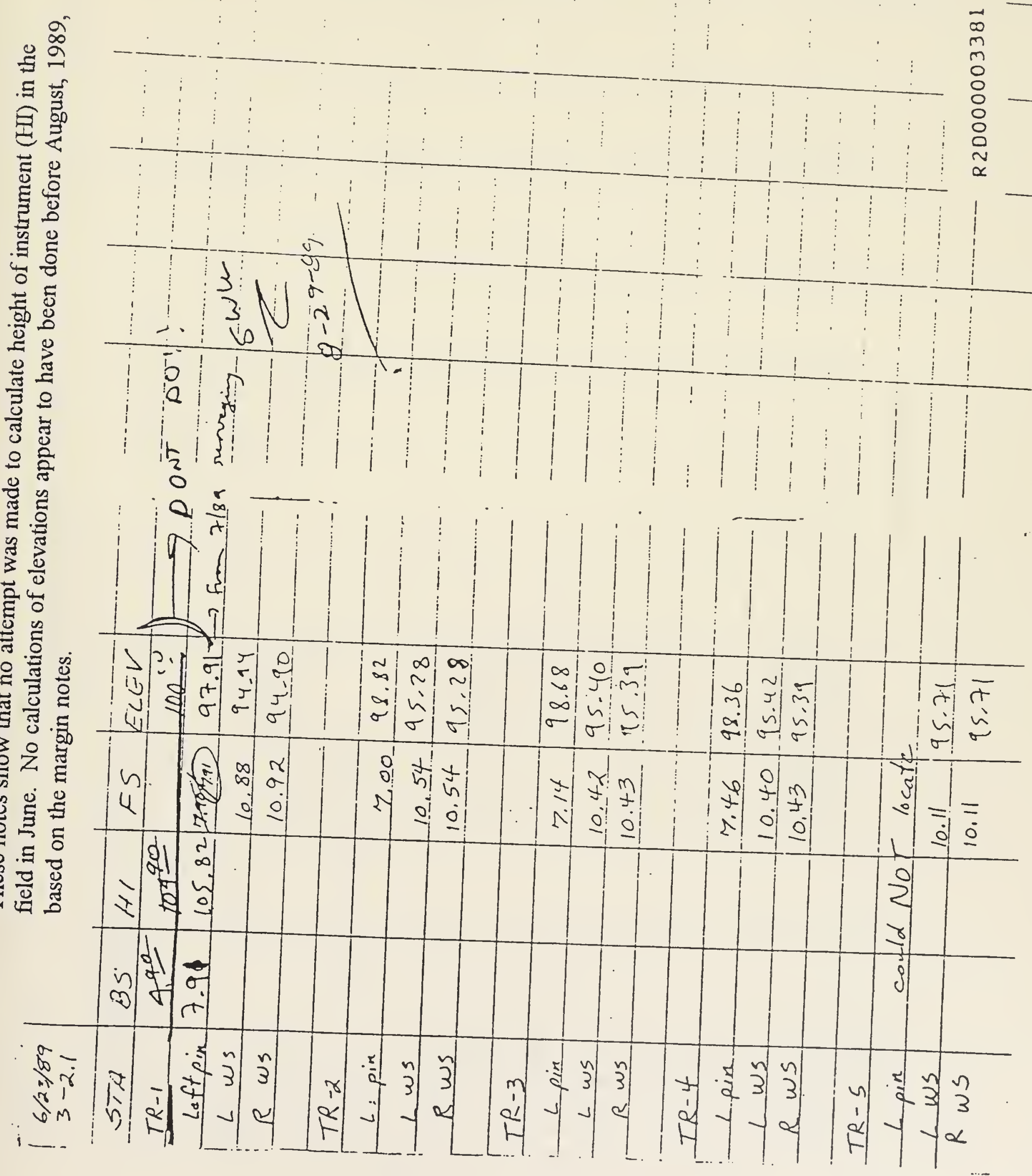





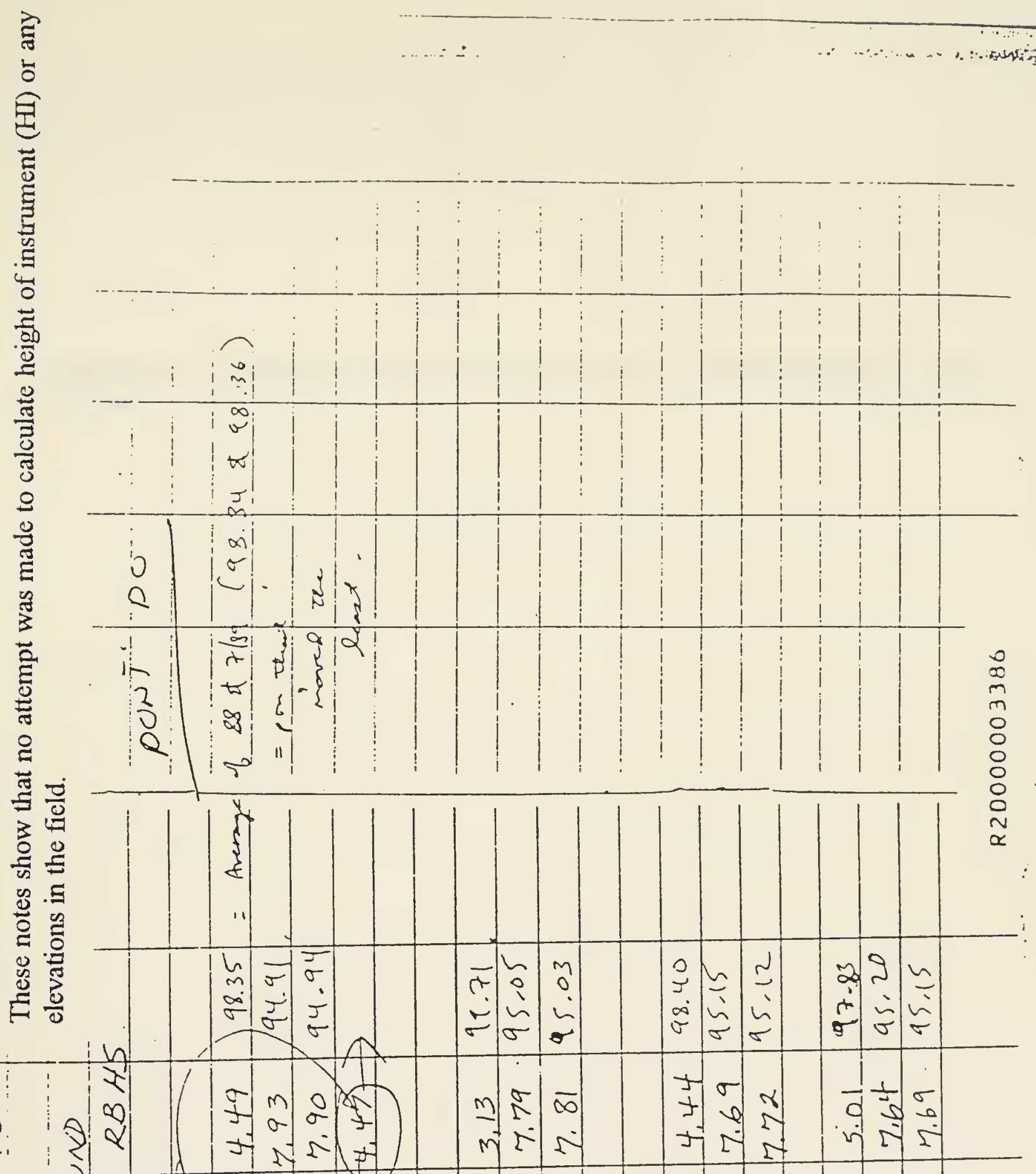

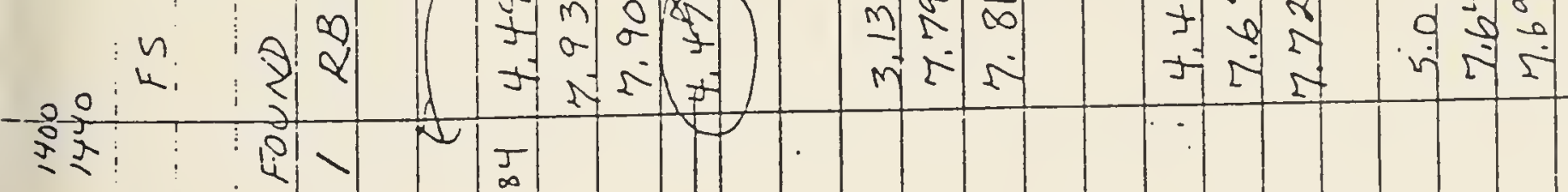

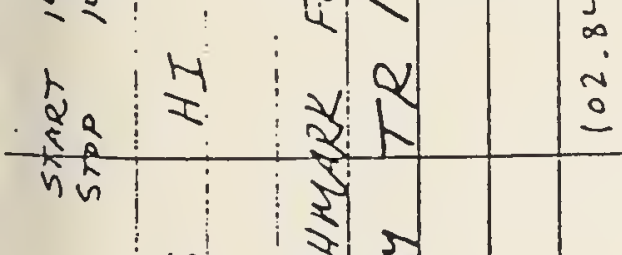
然 

Appendix 4. Summaries of surveyed elevations from 27 sites, compiled by EA after 3 field trips. 

EA Engineering, Science, and Technology, Inc. Westem Regional Operctions

41 Loroyette Cracto

Lofayette - Collfomb • 94549

(415) 283-7077 (teo

(415) $283-3894(100)$

PLEASE DELIVER TO:

Name: SIR WOLFFMAN

Prono: (206) 869 2914 Fax: (206)

Subjoct:

H you do nol recoive all pages clearty. call: ME

at: as soon as possible.

SENTBY:

Neme:

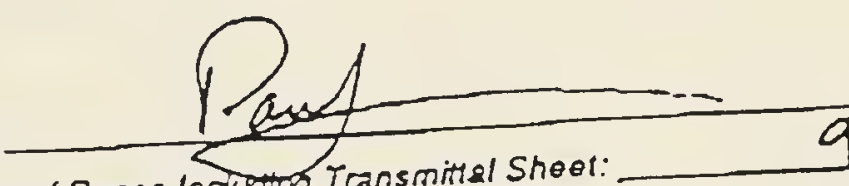

Number of Pages Indurmb Transmitial Sheet:

Delo:

Time:

Projod Code:

Briel Mossago:

$A$ written summary of field notes done by $E A$. Numerous discrepancies are included at most sites. 


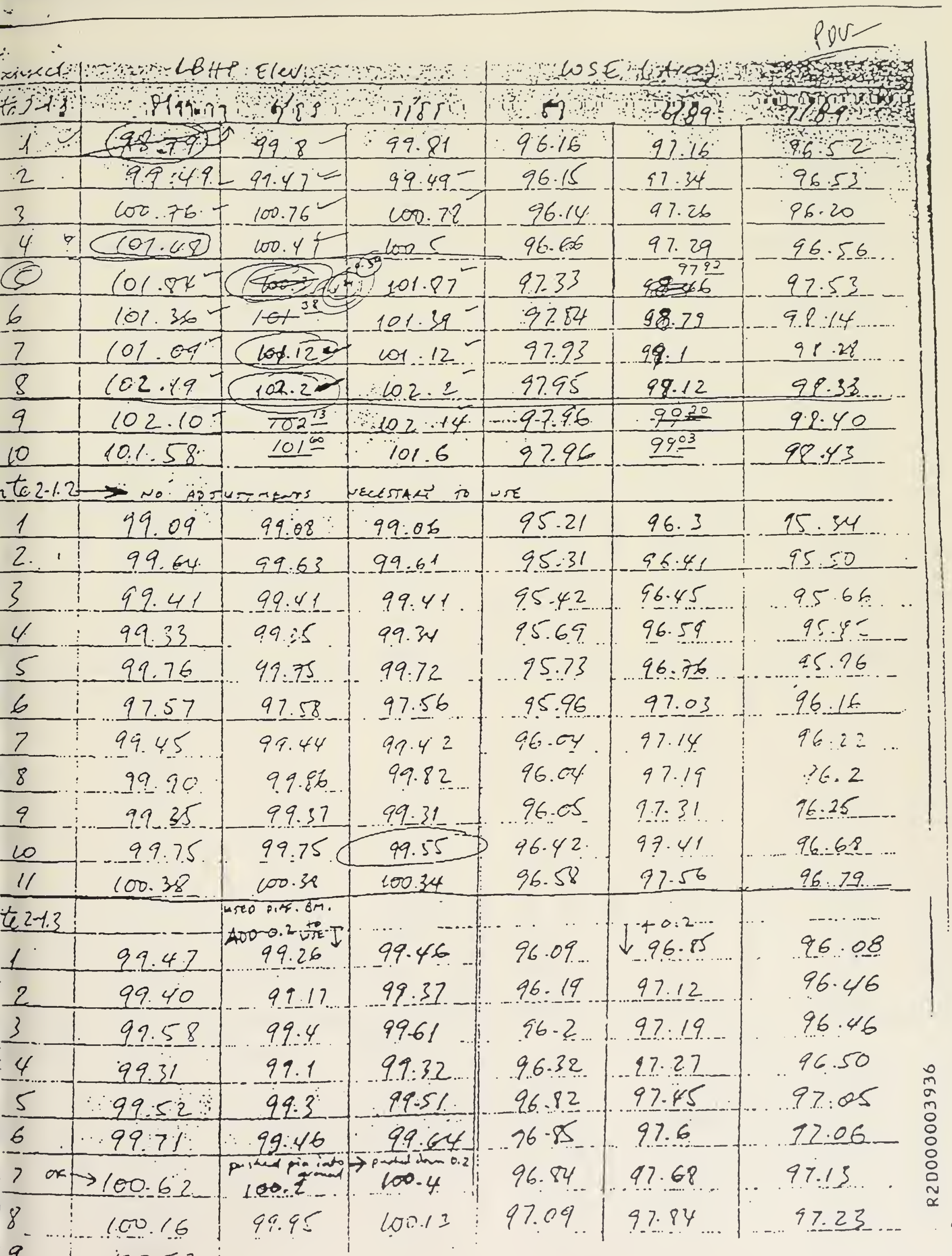





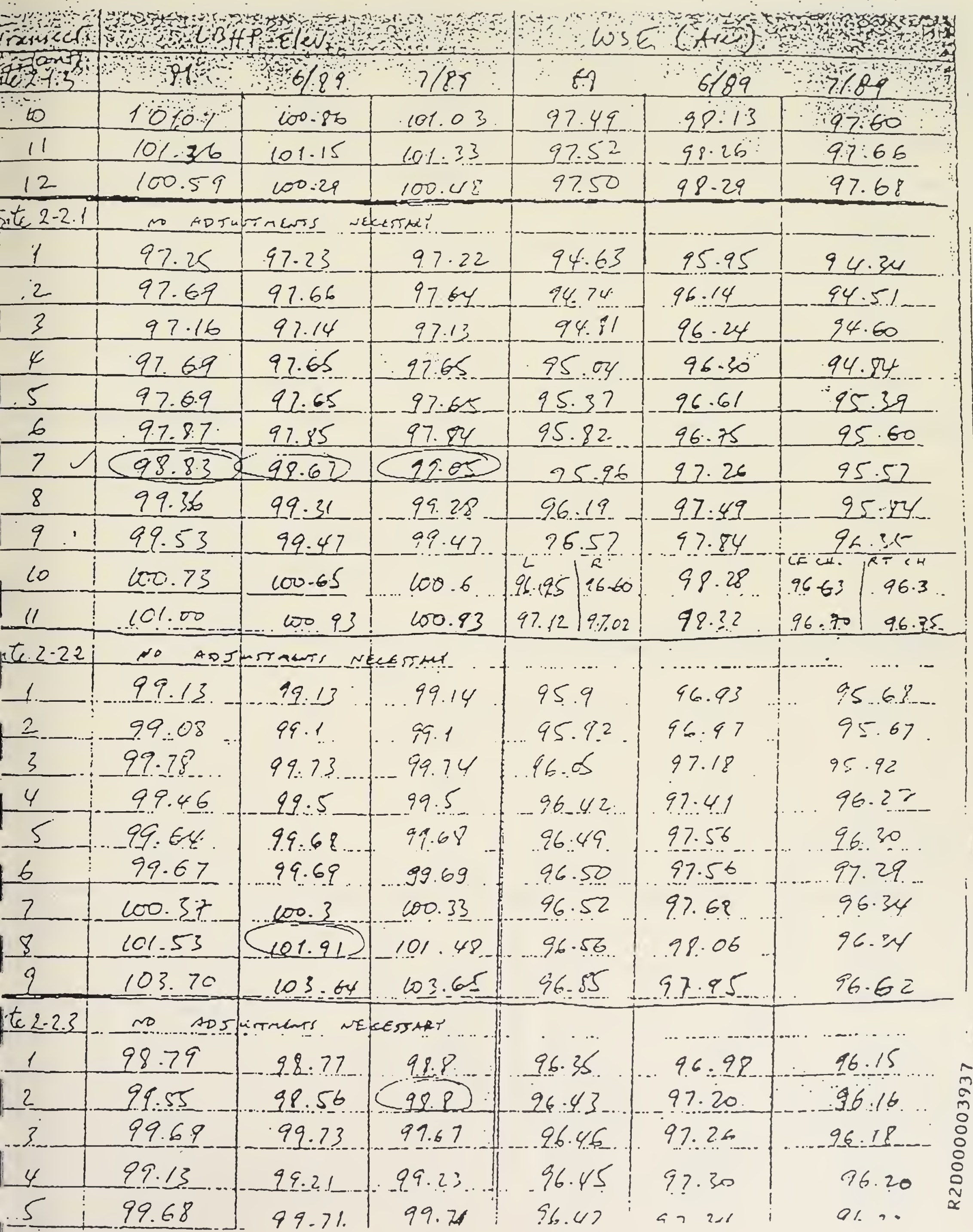





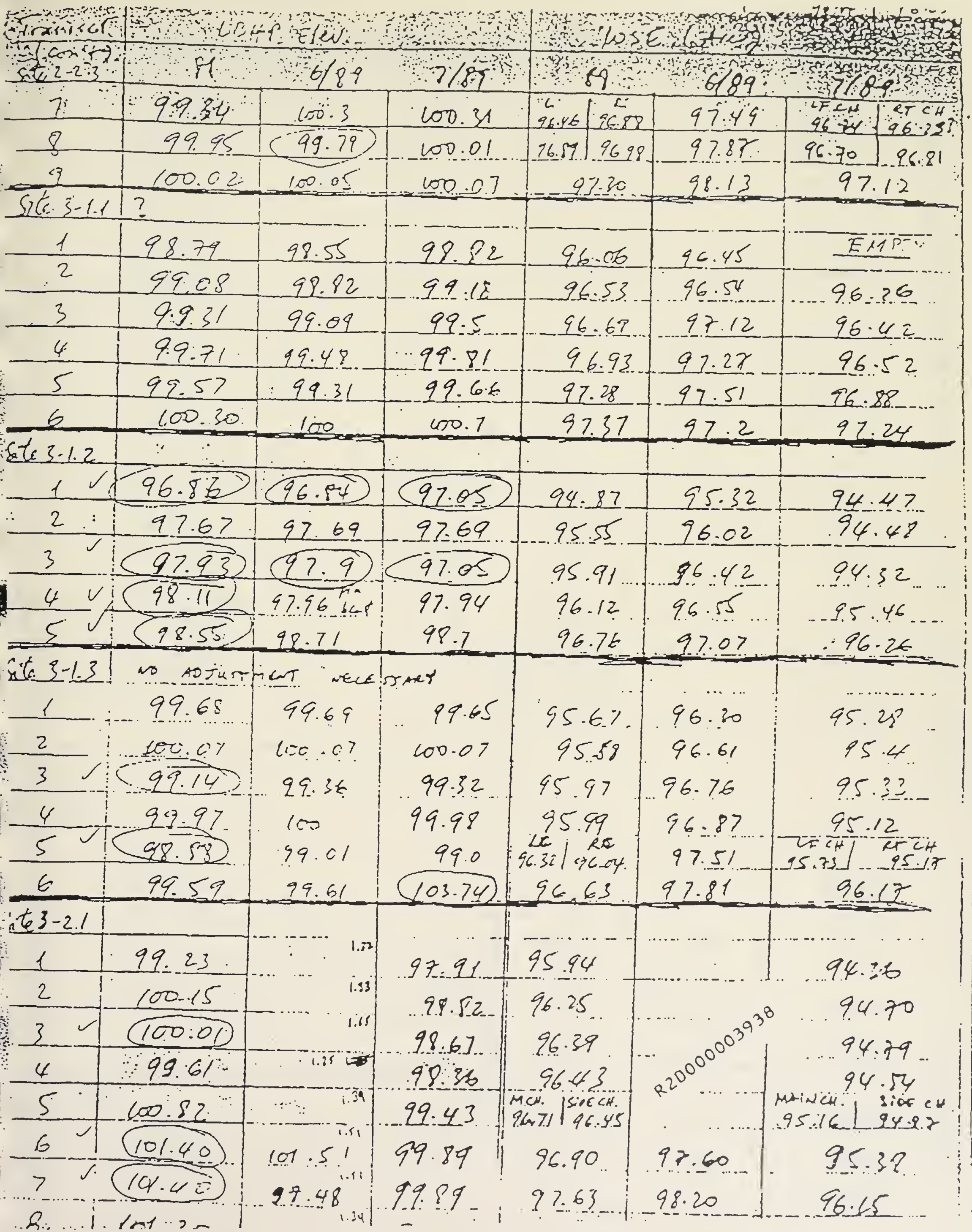






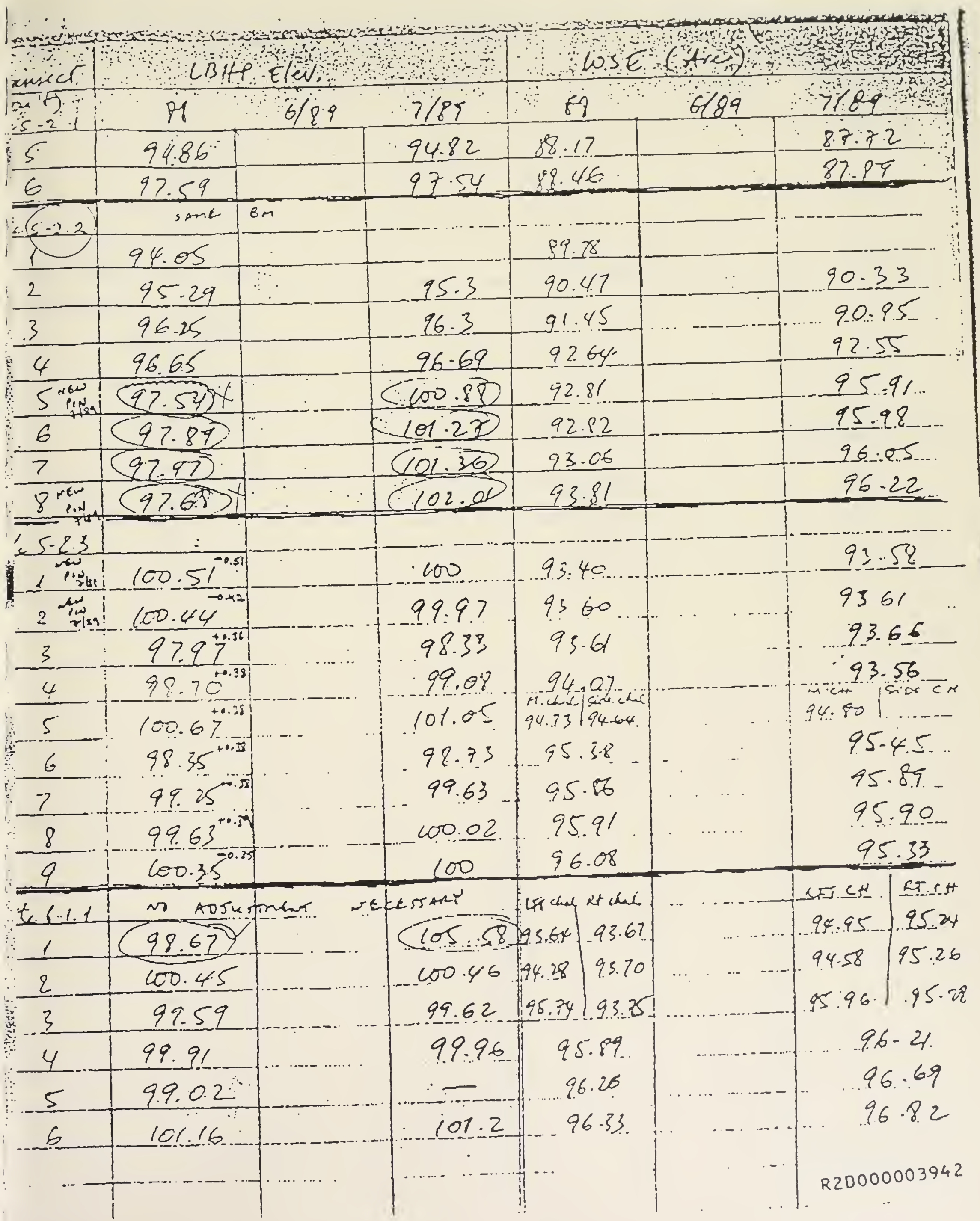



